\title{
Recognising 'True' Leadership: The Theory of Natural Born Leadership
}

\author{
Brian Haraida \\ Founder, Natural Born Leadership Institute \\ 7 Cambridge Terrace Hillbank \\ South Australia 5112, Australia \\ Professor Eddie Blass \\ Torrens University Australia \\ Wakefield Street \\ Adelaide \\ South Australia 5000, Australia
}

\begin{abstract}
This paper presents a new leadership theory which challenges the premise that leaders are born or made, and that some people are great leaders while others are not. The paper is founded on the belief that everyone is born a leader and that circumstances, our development and our opportunities in life develop our leadership ontology. Founded on the notions of courage, conviction and balance, Natural Born Leadership theory (NBL) separates leadership from notions of power, the need for followers, and a predetermined position or sphere of influence, and grounds it firmly within the individual, their ontology and their aspirations. Based on theoretical development stemming from years of working in, working with, and observing behaviours in competitive and collaborative sports, the theory presented in this paper is now being utilised in business coaching and having a truly transformational impact.
\end{abstract}

\section{Introduction}

Most leadership theories will recognise Nelson Mandela, Mohatma Gandhi, and Mother Teresa as shining examples of great leaders in our historical past. Many will also consider Adolf Hitler, Mussolini and even Donald Trump as being great leaders, when the theory alludes to personality traits or charisma; or is dependent on the scope of outcome achieved, such as the number of followers or scale of impact; or the zealousness with which people follow them unquestionably. But are the latter three mentioned here truly great leaders or are they simply good at manipulating leadership skills? Is it time to separate the process and skills of leadership as it is enacted in organisations and society from the embodiment of leadership itself? The argument of whether leaders are born or made has been and continues to be a means by which people adjudicate what is acceptable leadership practice and justify the dark side of leadership which they appear prepared to accept. But what if it is not one or the other -what if it is both? What if everyone is born a leader and has the opportunity to further develop their leadership disposition, skills, processes and develop their leadership abilities further?

Natural Born Leadership theory argues that everyone is born a leader, but whether that leadership potential is fulfilled, and in what capacity and circumstances, depends partly on context and partly on how the individual themselves develops. A Natural Born Leader (NBL) has Courage, Conviction and, above all, Balance and it is this that differentiates the true leaders from those who are simply in power or have exerted power. The separation of power and leadership is key in this theory, as is the independence on followers. Natural Born Leaders need not have followers, as achieving the ultimate balance in leadership would be to have others 'being' with you rather than 'following'.

This paper separates the notion of leadership from power, and thereby also disassociates the notion of followers from leadership, and firmly grounds the notion of leadership in the leader themselves. In doing this, it offers individuals and organisations new ways to conceptualise leadership that separate the process and routine of management in a hierarchical form from the innovation and vision and action that is leadership. The paper is inspired by the experience of a professional sports person who has worked with, worked in and works to develop competitive and collaborative sports leaders, and has decades of experience in business management in both the commercial and voluntary sectors, and whose early exposure to the notion of leaders being born or made as a dichotomy left him feeling somewhat disenchanted with the commonly promoted notion of leadership, and how leaders are developed, and hence has focussed his work through professional sports and organisational leadership to the development of this theory. 


\section{What influences people to fulfil their leadership potential?}

Martins (2018) differentiates between natural phenomena, collective phenomena and institutional phenomena in his study of leadership and power. Natural phenomena being those that occur naturally through the course of living, collective being those that occur through our interacting with others throughout our lives, and institutional being those that occur within organisations that are specifically structured to influence how we interact with others in our lives. Both the collective and institutional phenomena can include the notion of culture, the shared societal norms that govern how we behave in our world. Culture is the shared ideas, customs and behavioural norms that develop amongst groups within societies and can be bounded by religion (eg Jewish culture), by location (eg Adelaide culture), by interest (eg theatre culture), by sport (eg rugby culture), or by something else a group may have in common (eg teenage culture). Whether the culture is collective or institutional depends on the structure, technology and power infrastructure within the group. Some cultures may stem from both the collective and the institutional realms, such as with religions where there is the religious population (the collective) and the organised practice of the religion (the 'church').

The cultures we experience as we grow up in society shape our understanding of leadership, power and how we should 'be' in the world, and can be one of the first factors that limit or promote our ability to fulfil the natural leadership potential we are born with. Our formative experience of the world will differ greatly according to which country, region or community we are born into, who are parents are and what their socio-economic status is, the religion of our parents, the history of our community, and the education level and cultural capital in our homes (Bourdieu, 1986).

Beyond these 'local' factors that impact upon us, there is also the concept of privilege. Johnson (2018) notes the paradox of privilege as being received by and benefitting individuals, but actually having nothing to do with the people themselves as individuals. McIntosh (2000) describes privilege as one group having something of value that is denied to others simply because they belong to a particular social category, rather than anything they have done or failed to do. An example, amongst many, that most people can relate to is that heterosexuals and whites can go out in public without having to worry about being attacked by hate groups, and men can assume they won't be sexually harassed or assaulted just because they are male, and if they are victimized, they won't be asked to explain their manner of dress or what they were doing there (Johnson, 2018:27)'. Because privilege is systemic, there is no way that people can be 'outside' of it, ie you cannot escape it because it is given to you, but you can choose to be in the system in a way that challenges or strengthens the status quo, ie you have choices as to how you use your privilege, and to what ends (Brod, 1989). Privilege is raised here simply to help explain why some people, more than others, develop their natural born leadership capability, noting that it is not about the individual, and it is not something that any individual has a choice over. It is simply part of the ontology of our lives.

Sometimes great leaders emerge in times of crisis or change, simply because people's tolerance of the status quo and the application of privilege reaches a tipping point and they choose to do something about it. Recent examples include Emma Gonzales and the other teenagers who spoke up against the American gun lobby after the Florida shootings, or Greta Thunberg and the school children striking for climate change to become a priority for politicians around the world, and Malala Yousafzai, the teenager shot for standing up for girls education who later won a Nobel Peace Prize. These are all example of Natural Born Leaders as the rest of this paper will demonstrate.

\section{Leadership as an ontology - a philosophy of being}

Fry and Kriger (2009) ask what would leadership theory look like if it was based on being rather than doing or having? They note that that enduring leadership theories that fill over 10,000 books on library shelves are either about behaviour and interactions (doing), or styles, traits and competences (having). While more recently we've seen the emergence of authentic leadership (see, for example, Avolio et al, 2004), ethical leadership (Brown \& Trevino, 2006), servant leadership (originally Greenleaf, 1977), and transformational leadership (Bass, 1995) these theories still focus on what is done with a shift to more inclusive behaviours, and what the leaders have, with the focus on 'have' having shifted to values and emotions. Even notions such as emotional intelligence (Goleman, 1998) focus on how we behave, and are noted as social constructions of organisations. But it is possible to behave in a leadership role, and have leadership constructs, and still fail to be a true leader. We need only look at the Australian Royal Commission into Banking for some current examples, or consider the 'bullies' that exist in key roles in your organisations. The focus of leadership theory on getting things done has limited the consideration of leadership purely to outcomes. And while achieving outcomes is a necessary condition of leadership, it is not sufficient. 
Leadership is a way of being - it is how we experience the world. A starting point for consideration is 'locus of control' (Rotter, 1954). Some people experience the world as a 'victim' in that life happens to them and they never seem in control of the circumstances or events that occur, never take ownership of any misfortune or outcomes of decisions they have made, and are happy to put good fortune down to luck.

They have an external locus of control. Others have an internal locus of control and take responsibility for everything that happens to them, if only because they put themselves in the situation that allowed the happening to occur, but more usually because they actively engaged in something to try to influence an outcome. Being able to frame the world with an internal locus of control is core to the notion of leadership, and it holds us both responsible and accountable for our actions and the impact they have on others.

The model of being-centred leadership proposed by Fry and Kriger (2009) offers 5 holonic levels of 'being' (the lower levels are subsumed within the higher levels) and has been developed from studying the philosophical routes of six major religions in the world. The pinnacle of their theory is the achievement of oneness, a form of self-actualisation that transcends the spirit, the soul and the body. The tone of their discussion is of this realisation transcending the notion of leaders and followers fostering greater equality and acceptance of others views and needs, and they question whether this can possibly occur within the structure of an organisation. They propose that 'from the non-dual level of being, followership and leadership are simply labels that overly constrain the possible role sets of individuals. In the ideal, individuals have the potential to enter roles as needed to enact leadership in specific moment-by-moment situational contexts' (Ibid, 1686). The connectedness that occurs through this understanding of leadership is reflected in Natural Born Leadership theory and is core to the notion of 'balance' discussed later.

While Natural Born Leadership theory may be challenging some of the core tenets of traditional leadership theories, there is a base of literature in the critical leadership field that supports the principles on which it is built. For example, in their discussion of the need to study leadership not leaders, in an attempt to move the argument away from leadership being bound within the individual, Crevani et al (2010) suggest that the empirical study of leadership should be based in a process ontology,focused on leadership practices as constructed in interactions. This need to explore the context of the leader in order to understand the leadership practice as an ontology supports the theory of Natural Born Leaders. Dinh et al (2014) also focus on leadership processes, and the factors impacting on how they are derived, in their review of emerging leadership theories to understand how leaders make organisations more effective rather than how they are perceived. They identify the need to focus on how the leaders think, feel and behave in response to changing events, that is how they are experiencing the world, in order to unite leadership theory and understanding more generally.

\section{Introducing Natural Born Leadership Theory}

The restriction of the concept of leadership to the organisation, or some political ambition, limits the contexts in which leadership occurs, is appreciated and is developed. It also limits the possibility that everyone can be a leader. For many people who are not in leadership roles in their workplace, they are involved in community leadership, family leadership, friendship group leadership and other interactions. Some people may never have a formally recognised leadership role, but their mere presence in a room is enough to 'lead' an outcome - for example, the person whose presence raises the sense of fun and joy in the workplace has an enormously enabling leadership role but is rarely recognised for it, while the person who stresses everyone out and is constantly depressed is well noted!

If everyone is born a leader then there is the opportunity for everyone to be a leader. While the context in which we have grown up may have limited our belief in our leadership ability and future, it does not have to be a self-fulfilling prophecy. Natural Born Leadership theory proposes that everyone can develop their innate leadership disposition within their context to make an impact and bring about change that is important to them. It requires the development of three mental capacities: Courage, Conviction and Balance.

Being a leader is about making an impact, hopefully positive, on others. It is about the way you experience the world impacting upon and influencing how others experience the world, and doing this in a purposeful, meaningful way to achieve an outcome. While the most developed form of this may be some spiritual self-actualisation that allows us to be at oneness, such oneness can be achieved on a smaller scale; and if the only outcome is a change for the individual themselves, this is still leadership. It is not dependent on power; not dependent on followers; but is grounded in personal agency. In the next sections we will explore in more detail the concepts of Courage, Conviction and Balance.

\section{Courage}

Courage is more than simply doing something you fear. For example, it takes Courage to do something rather than just talk about doing it; it takes Courage to step outside your comfort zone to do something different;it takes Courage to speak up about an issue and then to tackle that issue in a new way; andit takes Courage to reach out and to try different 
things. Sometimes people think we're being really courageous when we don't think we are at all, and other times people don't recognise how courageous we are being. This is because external perceptions of Courage differ from our internal perceptions.

Ralph Waldo Emerson (1803-1882) founded the transcendental movement that challenged traditional religion through the church by proclaiming that humans have the ability to transcend the materialistic world and way of being, and can become conscious of their self, their soul and enlightened self-awareness that underpins freedom of action and the ability to change one's world according to their ideals and conscience. While the idea of natural born leaders does not necessarily conflict with organised religion, it does rely on individuals having the Courage to follow their own path, develop their own sense of consciousness and becomes consciously self-aware. This requires the Courage of a baby bird to learn to fly when they are thrown out of the nest, or take the leap themselves, as they either learn to fly or hit the ground. Emerson appreciated that to not simply following the path already set, but to leave the path and make your own trail is an enormous accomplishment (Emerson, 1841) and takes courage. And this is what Courage is to natural born leaders. It is finding your own path and taking it.

Hannah et al (2011) note that modern organisations are morally complex environments and hence the need for moral Courage in leaders to navigate the environment as authentic leaders. Lee\& Elliott-Lee (2006) argue that courageous leaders require excellent conduct of others because they model that themselves. They propose cowardice as the opposite, which leads us to live in fear. Living in fear is 'being a prisoner to our own weaknesses, constantly waiting for the next injustice' (ibid:2).SoCourage is about having the moral fortitude to refuse to live in fear, and by addressing the sources of fear, injustice is irradicated. This linking of fear and injustice is something we will return to when we consider balance later.

Moral Courage is not sufficient for Caldwell et al (2015) who view moral courage as leading in a manner that is honouring duties and values of stakeholders including society, while being virtuous is the pursuit of positive outcomes and maximising wealth creation. They identify virtuous leaders as having character, courage and compassion, as well as being competent, committed and clear in what they are setting out to do. They view Courage as being willing to challenge the status quo and established paradigms to keep the organisation moving forwards rather than falling behind the times. This almost infers that simply leading an organisation to a survival outcome is sufficient as the complexity and market uncertainty that organisations face mean that lacking Courage to move forwards will inevitably result in failure.

Interestingly,perception of Courage may be sufficient for leaders rather than acts of Courage. Palanski et al (2016) found that the context of adversity may be enough for others to perceive Courage, building on the idea of an external view of Courage. They note that 'a leader might be seen as being more courageous simply by being in a high adversity situation, regardless of his or her actual behavior' and 'that behavioral integrity does cause perceptions of behavioralCourage to some extent' (ibid: 306). Lopez (2018) claims that Courage is positively related to vulnerability in her study of 296 self-identified organisational leaders. So being seen as vulnerable, facing adversity and under the pump, may be enough for others in an organisation to perceive a leader as courageous - but it is not simply the perception that counts for Natural Born Leaders, it is the action.

Natural Born Leaders act courageously in that they have the Courage to act, or not act, if that is their choice. Courage amounts to (in)action as it is all too easy for people to have beliefs, ideas and convictions, but then allow (in)action to stifle their achievement of an outcome. In particular, nobody knows when someone didn't act, because nobody knows what the act would have been. Having Courage is a way of being that leads to action or definite inaction, and employing action wisely and with purpose is a skill that develops over time. Martyrdom is not Courage, whether it is walking away from an organisation because you don't agree with its actions, or actively sabotaging an action anonymously at the risk of being fired if found out. Courage is finding the voice to raise issues and challenge actions in an appropriate way, at an appropriate time, and in a manner that brings about the outcome you desire. In this sense, Courage is tempered by balance, as discussed later in the paper.

\section{Conviction}

Warren Bennis (1999:20) claims 'Every effective leader I've known is passionate about what he or she is doing. The time and energy devoted to work demand a commitment and conviction bordering on love.' Saar and Hargrove (2013) see a failure to commit as the number one reason for leadership failures in organisations. They view conviction as being a relentless focus on trying again and again until something works because everything within you is aligning to say it will. It is a self-belief stemming from self-awareness and experience, and it is not going to be stopped at the first hurdle by doubt. 
It is also tolerating poorer performance outcomes initially when implementing a change or transformation, as the process of changing is likely to take time and require shifts in perceptions and measurements in order for a wider group of stakeholders to appreciate the nature and outcomes of the change. Sticking with the change through this process requires conviction. Conviction is cited as a feature of authentic leadership, spiritual leadership, servant leadership and other leadership theories, and has a values-based root to its application. 'Authentic leaders do not take on a leadership role or engage in leadership activities for status, honor or other personal rewards.

Rather, they lead from a conviction' (Shamir \&Eilam, 2005: 397).Drawing on Aristotle's notion of Eudaimonia, they suggest that 'when people are eudaimonically motivated, they are fully engaged both in their own self-actualization and in using their virtues, talents and skills in the service of the greater good' (ibid). That is, authentic leaders are interested not only in being all that they can be but also in making a difference and as such, their actions align, so what they say is what they do.

Conviction is also important when considering the role of followers in leadership theory. Critics of leadership theorists note that leadership relies upon an element of systematic stupification of followers; that is it involves subordinates refraining from being particularly reflexive, thinking in wider ways or from engaging with the ambiguities. This is all seen as responsibilities of the leader. Being a follower, one should be disinclined from thinking independently and deviating from the ideas of the leader. Instead one should be prepared to accept that the leader is doing most of the difficult cognitive tasks. The job of a follower is to follow the visions, objectives, definitions of the situation and direct instructions set out byLeaders' (Alvesson \& Spicer, 2013: 184). Demanding absolute compliance from followers generates stupidity in organisations. If a leader has conviction, then they would want their followers to share this conviction and be active participants in achieving the goal set rather than stupidly going on the journey.Natural Born Leaders with conviction welcome the reflexive challenge of others as they assess the issue at hand, and are willing and able to flex their process pathway in light of feedback and ideas from 'followers'. Followers are not a subordinate role to be controlled; they are a bunch of like-minded individuals committed to the same pathway, bringing diverse views and challenges to keep the pathway as broad as possible.

Uhl-Bien et al (2014) argue that without followers there is no leadership and hence having followers is a necessary, but not sufficient, condition of leadership. Meindle et al (1985) claim that leadership is actually a social construct created by followers when there is over-attribution of outcomes of a group process to the person who is the focal point of the groups attention, ie the leader - and hence without followers the concept of the leader doesn't even exist. But does one always have to have followers when they embark on their leadership journey?

At the other end of the spectrum, Follet (1927) sees the relationship between leaders and followers as an 'intermingling of forces' rather than a dominant relationship, which is furthered as a notion in Hollander's (1993) relational theory of leadership, and leader-member exchange theory (Graen et al, 1982). This intermingling is closer to the role of 'followers' in Natural Born Leadership theory. The notion of a follower itself is dis-abling as it takes agency away from the person who is 'following' by assuming a power relationship rather than choice of shared conviction. For example, it could easily be argued that the 'first follower' is a leader in their own way, as is anyone who makes a change of some form to 'follow' an ideal. A change for one person inevitably means a change for others, and in that respect every person who enacts a change in their life is leading a change for others, whether they choose to follow or not.So leadership requires conviction to bring about a change, whether as the first, or the first follower, or simply as a courageous step for you in joining a movement already gaining momentum. Your deliberate action will bring about change for you and for others, and this is at the heart of Natural Born Leadership.

\section{Balance}

The notion of balance as being key in a leadership theory is not the norm. In fact, most leadership theories strive for imbalance (see, for example, Sternberg, 2007; Grint et al, 2016). They seek an imbalanced power relationship; an imbalanced personality dominated by traits that only a few will have; an imbalanced entitlement that privileges some to be leaders over others; or an imbalanced world which motivates leaders to pursue change.

Mention 'balance' in most organisations and people generally think of work-life balance. Due Billings (2013) notes that for many people their social identity is bound up with their work, and they live to work rather than work to live, and that leaders giving their team autonomy can lead to them being over-committed and burning out, rather than achieving a greater sense of work-life balance. Often you hear a rhetoric of caring and people being expected to manage their work-life balance, but the reality of the culture in the organisation is competitive so those that do leave 'early' are seen as less ambitious, less 'everything'. Hence the promotion of 'balance' as an ideal is actually undermining balance as a practice. 
While there is much more to balance in leadership than work-life balance, it is a good indicator of whether balanced leadership is occurring. For example, in some workplaces it is frowned upon to need to stay late to work after office hours because it is seen as a sign that you cannot organise yourself to complete your work during the working day, rather than a good thing because you are showing extra commitment.So what exactly is balance in leadership? In Natural Born Leadership theory it is the idea of having the right view to have the right intention behind an action, and hence the right conduct occurs through the quality of the action occurring. In short, right view equals right conduct, and hence both outcomes in the above example could be appropriate depending on the individual, the organisation and the balance that is being achieved at any particular point in time.

It needs to be right view equals right conduct for all parties concerned. Ellis (2013) argues that it is the duty of every leader to develop their ability to balance results and relationships, as much as they may prefer one over the other. This applies to everyone in an organisation, not just the leaders, and good Natural Born Leaders will council out of the organisation members who do not appreciate this.

Kelly (2014:915) argues that 'leadership as a term isempty, but this emptiness is not without effect or consequence. As an empty signifier,leadership provides the possibility for filling the gap that exists between language andour experience of reality, and in so doing provides a space of productive fantasy through which hopes for a better future or a better world can be expressed, but perhaps neverrealized.' This space is where right view, right conduct sits. Leadership theories generally refrain from passing judgement on what it is that the 'leader' is leading; and they refrain from passing judgement on the manner in which the 'leader' leads. While coercion is largely seen as an overuse of power, leaders can still be recognised as 'great' for the means by which they got to a position where their coercive powers could go uncontested.

The 'Responsible Leadership' literature goes some way to addressing this concept of balance as the concept arose to address the unethical behaviour that was being recognised as leadership and the need for a differentiation in leadership theory that recognised such behaviour as unacceptable. MacTaggart \& Lyneham (2018) note that the authors publishing Responsible Leadership theory (RL) were motivated to either open leadership systems to include more people, extend leadership focus for the greater good, or to promote leadership with strong ethical grounding. They also note, in their review of RL literature, that RL theory is associated with the extant ideas and approaches already known, and hence they are an additional slant on, or addition to existing theories, rather than being a theory of its own.

But RL doesn't go far enough in that it is still situated within traditional views of what and who a leader is. In Natural Born Leadership theory, the notions of 'Natural' and being 'Born' are important. Natural in terms of being part of larger natural ecosystem where we should seek to leave the ecosystem in at least the same state, if not a better state, as an outcome of our actions; and Born in terms of our being human, and embracing a sense of humanity that sees all humans as equal.

There is no room for discrimination of any form in Natural Born Leadership theory, and profiting at the expense of the planet is also not accepted. It is too easy to achieve an outcome at the expense of others or the planet - and hence this type of leadership is not recognised as 'good' within Natural Born Leadership theory. Valentine (2015) talks about 3 poisons that are collectively responsible for the pain and suffering in the world, which translate to all contexts: Greed, Hatred and Delusion. The need for self-awareness to realise when these are driving a leaders behaviour is paramount. Block (2014) argues that pausing to reflect with self-awareness on the intentions behind a leaders actions allows them to be ethically focussed, politically mitigated and assuaged if they realise their intentions were inappropriate. Natural Born Leaders are not superhuman - they are not immune to the emotions of hatred, greed and delusion - but they develop the self-awareness to realise their impact and make decision to act in spite of these, rather than to incite them.

Natural Born Leaders are also happy to recognise that they are not always 'the leader' in a group, but rather may be leading for some aspects and not for others. The possibility of leadership beingtransient is supported by DeRue and Ashford (2010:635) who found that "when there is convergence in shared leadership-structure schemas, leader and follower identities flow back and forth within the relationship based on a mutual understandingthat granting a leader or follower identity to one individual does not preclude the possibility that theidentity will be claimed by and granted to others.'

The notion of right view leading to right conduct allows leaders to step back when necessary and then step up again as situations need. A balanced leader does not have to be leading all the time; they have the self-awareness and humility to know when to step up and when to step back. This is the ultimate expression of balance, because leading is not about the 'leader' per se, but about the situation they are leading. 


\section{Conclusions}

Kelly (2014: 906) claims that 'unlike other forms of description or expression, 'leadership' does not signify anything specific or fixed, but instead serves to create the conditions of possibility for many competing and complementary definitions, meanings and interpretations.' As such he believes that leadership is more of an ideology (a system of ideas) than an ontology (a philosophy of being), and it is somewhat mythical in its identification. He argues that as leadership theory has moved from the individual to the relational influence of others, it can no longer be bounded as an ontology as there are too many external influencing factors at play. Natural Born Leadership theory sees these external influencing factors as key to the ontology of leadership, as it is how the individual responds to these that determines the extent to which they choose to be a leader in that context or not. For NBL, leadership is not necessarily a constant - it is a choice.

Crevani et al (2010) see leadership as a process of becoming with every possible interaction with others being a potential leadership experience. This moves the notion of leadership firmly away from outcomes, and much more in the reality of being.

In separating power from leadership, Jones and Yorke (2016) note that effective leaders have power, but not all powerful people are effective leaders. French and Raven (1959) uncovered 5 bases of social power, and while legitimate, expert and referent power are listed, so are punishment and reward, noting the use of power in a 'carrot or stick' approach to ensure that followers do as required. When a leader is reliant on power, they are seeking domination, and their leadership becomes 'about me' rather than 'about us'. It is therefore key in Natural Born Leadership theory, that power is seen as completely separate to leadership, and indeed is not a factor in consideration. Natural Born Leadership theory neglects the notion of power in leadership; it is noticeable in its absence. Someone does not have to have power in order to be a Natural Born Leader - it is not a necessary condition.

While Natural Born Leaders have Courage and Conviction, this is not at the expense of being open to criticism. It is not Conviction to the point of narcissism. There always need to be some doubt and uncertainty in order to continually critically review behaviour over time to ensure you are moving on the path you choose. Being ignorant to the possibility that you may have missed something closes the opportunity to pivot and shift, and Conviction turns into a crusade. Critical review allows our beliefs to become more adequate (Harter, 2013). This balance of having the Courage to be truly questioned, and to truly question yourself, with the Conviction to make the decision to take the path you choose is in constant flux, and having the humility to acknowledge when you have been wrong and shift the path accordingly is part of the process of becoming.

The core of Natural Born Leadership theory, therefore, is the presence of Courage and Conviction under the auspices of Balance. Everyone is born a leader; to draw out their Natural Born Leadership capability, the focus needs to be on the development of their self-awareness, to understand their Courage, find their Conviction, and constantly seek to maintain their Balance in a world where the norm, pressure and temptation for imbalance is constantly present. It is not surprising, therefore, that most leaders we meet in our lives would fail to meet the Natural Born Leadership criteria, and why there is so much organisational dysfunction, bullying, discrimination and exploitation in the world. While Natural Born Leadership may not be the panacea to all of the world's problems, it does at least give a perspective from which they can be acknowledged and addressed.

\section{References}

Alvesson, M. \& Spicer, A. (2013) Does leadership create stupidity? In Lemmergaard, J. \&Muhr, S. (Eds) Critical Perspectives on Leadership Emotion, Toxicity, and Dysfunction. Cheltenham, UK: Edward Elgar Publishing. Ch 11.

Avolio, B.J., Luthans, F. \& Walumbwa, F. (2004) Authentic leadership: Theory building for veritable sustained performance. Working paper, Gallup Leadership Institute, University of Nebraska, Lincoln.

Bass, B.M. (1995) Theory of transformational leadership redux. The Leadership Quarterly. 6, 463-78.

Bennis, W. (1999). The leadership advantage. Leader to leader, 12(2), 18-23.

Block, B. A. (2014) Leadership: A Supercomplex Phenomenon, Quest, 66(2), 233-246,

Bourdieu, P. (1986) The forms of capital. In Richardson, J. (Ed) Handbook of Theory and Research for the Sociology of Education. New York: Greenwood.

Brod, H. (1989) Work Clothes and Leisure Suits: The Class Basis and Bias of the Men's Movement. In Kimmel, M. \& Messner, M. A (Eds) Men's Lives. New York: Macmillan.

Brown, M.E. \& Trevino, L.K. (2006) Ethical leadership: A review and future directions. The Leadership Quarterly. 17, 595616.

Caldwell, C., Hasan, Z., \& Smith, S. (2015). Virtuous leadership-insights for the 21st century. Journal of Management Development, 34(9), 1181-1200. 
Crevani, L., Lindgrem, M. \&Packoff, J. (2010) Leadership, not leaders: On the study of leadership as practices and interactions. Scandinavian Journal of Management. 26, 77-86

Dinh, J. E., Lord, R. G., Gardner, W. L., Meuser, J. D., Liden, R. C. \& Hu, J. (2014) Leadership theory and research in the new millennium: Current theoretical trends and changing perspectives. The Leadership Quarterly. 25, 36-62

Due Billing, Y. (2013) Happily working until they drop: when there is no longer a balance between stress and fun - a task for leadership. In Lemmergaard, J. \&Muhr, S (Eds) Critical Perspectives on Leadership Emotion, Toxicity, and Dysfunction. Cheltenham, UK: Edward Elgar Publishing. Ch 7.

Ellis, L. (2013) Understanding your leadership balance. The Journal for Quality and Participation. 35, 4-8.

Emerson, R. W. (1841) Self-Reliance. Reproduced in Myerson, J. (2000) Transcendalism: A Reader. New York: Oxford University Press.

French, J. R. P. \& Raven, B. H. (1959) The Bases of Social Power. In Cartwright, D. et al (Eds) Studies in Social Power. Ann Arbor: Institute for Social Research. Pp150-167.

Fry, L. \&Kriger, M. (2009) Towards a theory of being-centered leadership: Multiple levels of being ascontext for effective leadership. Human Relations. 62(11), pp1667-1696.

Graen, G., Novak, M. A., \&Sommerkamp, P. (1982). The effects of leader-member exchange and job design on productivity and satisfaction: Testing a dualattachment model. OrganisationalBehaviourand Human Performance,30(1), 109131.

Greenleaf, R.K. (1977) Servant leadership: A journey into the nature of legitimate power and greatness. New York: Paulist Press.

Grint, K., Jones, O. S., Holt, C., \&Storey, J. (2016). What is leadership. In Story, J., Hartley, J., Denis, J-L., Hart, P. \& Ulrich, D. (Eds) The Routledge companion to leadership. Taylor \& Francis.

Hannah, S. T., Avolio, B. J., \& Walumbwa, F. O. (2011). Relationships between authentic leadership, moral courage, and ethical and pro-social behaviors. Business Ethics Quarterly, 21(4), 555-578.

Harter, N. (2013) Socrates' mission against reproachable ignorance: leaders who refuse to acknowledge their ignorance and instead suppress criticism. ? In Lemmergaard, J. \&Muhr, S. (Eds) Critical Perspectives on Leadership Emotion, Toxicity, and Dysfunction. Cheltenham, UK: Edward Elgar Publishing. Ch 9.

Hollander, E. P. (1993). Legitimacy, power, and influence: A perspective on relational features of leadership. In M. Chemers, \& R. Ayman (Eds), Leadership theory and research: Perspectives and directions. San Diego: Academic Press.pp. $29-47$.

Johnson, A. G. (2018) Privilege, Power and Difference $\left(3^{r d} E d n\right)$. New York: McGraw-Hill.

Jones, A. M. \& Yorke, S. L. (2016) The Fragile Balance of Power and Leadership. Journal of Values Based Leadership. 9(2), pp127-142.

Kelly, S. (2014) Towards a negative ontology of leadership. Human Relations. 67(8), pp. 905-922.

Lee, G., \& Elliott-Lee, D. (2006). Courage: The backbone of leadership. John Wiley \& Sons.

Lopez, S. O. (2018). Vulnerability in Leadership: The Power of the Courage to Descend. @ https://digitalcommons.spu.edu/iop_etd/16/ (accessed 23/2/19).

MacTaggart, R. W. \& Lyneham, S. A. (2018) An integrative literature review of Responsible Leadership: Knowns, Unknowns and Implications. Journal of Leadership, Accountability and Ethics. 15(3), pp56-69.

Martin, N. O. (2018) An Ontology of Power and Leadership. Journal for the Theory of Social Behaviour. 48(1), pp83-97.

McIntosh, P. (2000) White Privilege and Male Privilege: A personal account of coming to see correspondences through work in women's studies. In Minas, A. (Ed) Gender Basics: Feminist Perspectives on Women and Men $\left(2^{\text {nd }}\right.$ Edn). CA: Wadsworth.

Meindl, J. R., Ehrlich, S. B., \&Dukerich, J. M. (1985). The romance of leadership. Administrative Science Quarterly, 30, 78102.

Palanski, M. E., Cullen, K. L., Gentry, W. A., \& Nichols, C. M. (2015). Virtuous leadership: Exploring the effects of leader courage and behavioral integrity on leader performance and image. Journal of Business Ethics, 132(2), 297-310.

Rotter, J.B. (1954). Social learning and clinical psychology. New York: Prentice-Hall.

Saar, S. S., \& Hargrove, M. J. (2013). Leading with conviction: Mastering the nine critical pillars of integrated leadership. John Wiley \& Sons.

Shamir, B., \&Eilam-Shamir, G. (2018). "What's your story?” A life-stories approach to authentic leadership development. In Leadership Now: Reflections on the Legacy of Boas Shamir. Emerald Publishing Limited.pp. 51-76

Sternberg, R. J. (2007). A systems model of leadership: WICS. American Psychologist, 62(1), 34-42.

Uhl-Bien, M., Riggio, R. E., Lowe, K. B. \& Carsten, M. K. (2014). Followership Theory: A Review and Research Agenda. The Leadership Quarterly 25(1): 83-104.

Valentine, M. (2015) 12 Pieces of Buddhist Wisdom that will transform your Life. @ https://buddhaimonia.com/blog/12pieces-of-buddhist-wisdom-transform-your-life accessed 1/3/19. 